\title{
Miranda
}

Revue pluridisciplinaire du monde anglophone /

Multidisciplinary peer-reviewed journal on the English-

speaking world

$18 \mid 2019$

Guerre en poésie, poésie en guerre

\section{Deaf People and Performance: the Example of Sirens}

An interview with Rosalind Hoy, Performer and Creative Producer of Zoo

Co Theatre Company

\section{Michael Richardson}

\section{OpenEdition}

\section{Journals}

\section{Electronic version}

URL: http://journals.openedition.org/miranda/18417

DOI: $10.4000 /$ miranda. 18417

ISSN: $2108-6559$

Publisher

Université Toulouse - Jean Jaurès

\section{Electronic reference}

Michael Richardson, "Deaf People and Performance: the Example of Sirens", Miranda [Online], 18|

2019, Online since 17 April 2019, connection on 16 February 2021. URL: http://

journals.openedition.org/miranda/18417 ; DOI: https://doi.org/10.4000/miranda.18417

This text was automatically generated on 16 February 2021.

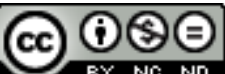

Miranda is licensed under a Creative Commons Attribution-NonCommercial-NoDerivatives 4.0

International License. 


\section{Deaf People and Performance: the Example of Sirens}

An interview with Rosalind Hoy, Performer and Creative Producer of Zoo Co Theatre Company

Michael Richardson

\section{Zoo Co : Website}

wearezooco.co.uk 
Fig. 1

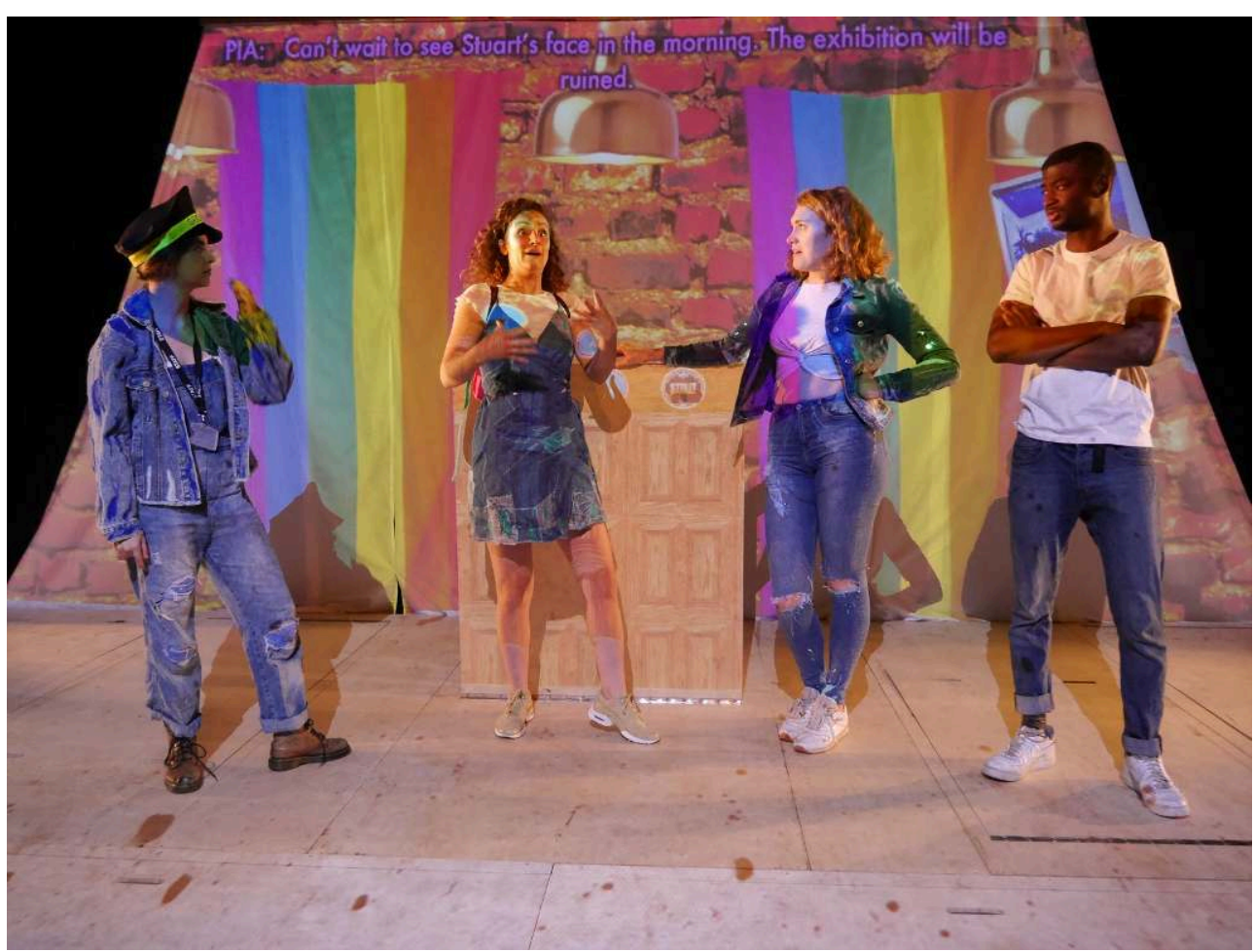

The cast of Sirens: ( $L$ to R) Florence O'Mahony, Fleur Rooth, Rosalind Hoy and Jamal Ajala Credits: Photograph by Yoona Park

\section{The Interview}

There is an inherent connection between deaf ${ }^{1}$ cultural practices and theatrical performance. Leith $(2016)^{2}$ has described the deaf community as 'corp-oral', using signed language storytelling for the transmission of culture from one individual to another, and Wilson $(2006)^{3}$ suggests that the addition of formality and convention transforms storytelling from everyday interaction to performance. From within the deaf community, Miles and Fant (1976) ${ }^{4}$ suggest that signed languages are naturally theatrical, often exaggerated in everyday conversation to produce a more dramatic visual language in a manner that can be harnessed on stage.

3 Unsurprisingly, there has been a strong tradition of theatre within the deaf community. At the amateur level, deaf schools and deaf clubs traditionally included their own drama societies, and in the UK and US these would compete in regional and national competitions. Professionally, the National Theatre of the Deaf ${ }^{5}$ (NTD) in the US was groundbreaking in putting deaf people and signed language on stage and in the public eye ${ }^{6}$, and this was matched in many other countries, including the British Theatre of the Deaf ${ }^{7}$ and the Theatre of Mimicry and Gesture in Moscow ${ }^{8}$, to name but two.

4 This picture is, however, only representative of the mid- and late-20th century. In more recent years, deaf theatre has been in decline. The closure of deaf schools and deaf clubs has removed centres of amateur activity, and funding cuts have curtailed the activities of professional companies, often terminally. Additionally, the almost ideological attachment of theatre venues to the sign language interpreted performance 
as a means of engaging deaf spectators with hearing (spoken language) theatre only contributes to alienating deaf people, as the technique typically employed is not considered effective by deaf spectators as a means of providing access ${ }^{9}$.

5 Interpreted theatre notwithstanding, there are still some examples of work that foreground deaf people and signed languages onstage, by companies that are either deaf-led, or at least led by deaf and hearing people together. Their ambition is not, however, the "deaf theatre" of Miles and Fant (1976), in which deaf actors play deaf characters who use a signed language to re-present elements of the deaf experience on stage. Instead, they create bilingual theatre using signed and spoken languages, and aim to offer equality of participation for deaf and hearing spectators. In the US for example, the NTD spawned Deaf West ${ }^{10}$, which reflects the linguistic diversity of the deaf community by working in both American Sign Language and spoken English. Similar work is created in the UK by, for example, Deafinitely Theatre ${ }^{11}$ and the Deaf and Hearing Ensemble ${ }^{12}$.

6 Funding for such companies is limited, and they rarely create more than one new production each year. In contrast, where companies are better resourced, the casting of deaf actors remains uncommon. Indeed, in the UK, it is only recently that deaf actors have joined the ensembles of the Globe Theatre in London and the Royal Shakespeare Company. Most regional producing venues, The Royal National Theatre in London and the National Theatre of Scotland are yet to follow suit, the latter despite the graduation of a cohort of deaf actors from the Royal Conservatoire of Scotland in 2018, and the earlier passing of the British Sign Language (BSL) (Scotland) Act in $2015^{13}$, which encourages the use of BSL by publicly funded institutions. Conley, a deaf writer, is unsure why theatre-makers do not use signed languages in theatre more often, particularly given their inherent ability to connect meaning to emotion. He suspects that fear of a negative response from hearing spectators prevents them from following in the footsteps of directors such as Peter Sellars and Robert Wilson in working with deaf actors ${ }^{14}$.

7 One company in the UK which is breaking the mould is Zoo Co. A small touring theatre company based in Croydon in the UK, Zoo Co decided to work with a deaf actor and incorporate BSL into their theatre making for their 2018 play Sirens, created for the 2018 Edinburgh Festival Fringe. Despite their long-stated aim being to "break down the barriers between mainstream theatre and theatre that is deemed suitable for people with different needs", by ensuring that "everyone has a seat at the table ... within our touring work, engagement models and organisation as a whole", this was a new departure for the company. Previously their drive towards high quality accessible performances had led them to focus on "a 'Relaxed Performance as Standard' model for all of our shows. This means that the usual, uptight rules that apply to being a member of the audience are relaxed. The show will stay exactly the same but if you need to get up, go out, come back in, make some noise, eat some food, or wriggle about, you are more than welcome to and you won't be picked out or called upon for doing so".

8 This open attitude is linked to a desire "to explore issues that are current, important and relevant to a diverse range of people through inventive and visual storytelling, comedy and clowning ... to play lightly with things that matter deeply". These interdependent factors made the idea of casting a deaf actor a relatively small step, and "2018 saw Zoo Co take a massive leap in its capacity to create accessible work, by 
creating our first ever BSL inclusive and deaf accessible show in a fully open rehearsal space".

The trigger for this development was the decision to base a new work on the Greek myth of the Sirens, characters, often mistaken for mermaids, "whose voices were so alluring that any sailor floating past couldn't help but throw themselves from their ships in order to get to them". Over time the Sirens have become "synonymous with negative portrayals of women ... we wanted to change this story and tell it from the perspective of these much neglected, often misunderstood women ... we began thinking about what would happen if the Sirens met a man who couldn't hear their voices. Although a 'fiercely feminist' show, we wanted to see the story from a male perspective too and see what an interaction between a Siren and a man might look like".

For Zoo Co, with its drive for accessibility, the decision to write a male character that couldn't hear meant "it was vital that we worked with a deaf actor to make the story believable and authentic to an audience and to the character". Deaf actor Jamal Ajala was cast as Tobi, the deaf character. This gave the company the opportunity in the creative process "to explore ways that a deaf BSL user might communicate with what can only be described as three 'aliens' at the beginning of the show". They could also demonstrate "how this new language becomes a lifeline for the three hearing characters [the Sirens] when it is their only way to communicate" without driving men to their deaths. In addition they were able to put elements of the deaf experience on stage. "Our work is created through improvisation and devising so it is inevitable that the actors' direct experiences inform what eventually goes onto the stage." Having Ajala within the company had a direct impact on the performance material. For example, in Sirens we see Tobi "ordering some food from a fast food chain ... and being scolded by the worker who said he'd been calling him for a long time". This represented a theatricalised version of a real incident from Ajala's life.

Developing and rehearsing Sirens was novel for Zoo Co not only as a source of material drawn from the lives of deaf people. In reality it was a "different experience from any of our previous rehearsal processes. It was so important that from the beginning everyone had an awareness of how to make this show as accessible as possible to all of our audiences". Linguistic difficulties were the most pressing. "We soon realised the challenges of a bilingual rehearsal room and the very different level of concentration it takes to communicate in BSL, especially when most of the room is very new to the skill! This meant we had to learn quickly, and we did. Following 6 days of lessons, the primary team had very basic BSL. We then leapt into a five-week rehearsal process, followed by a tour and a month at the Edinburgh Festival Fringe. We tried to use as little English as possible to ensure that everyone in the room could be included in conversations, and when that became tricky, we were fortunate enough to be supported by two BSL/English interpreters who could make sure that everything was clear."

12 The interpreters were not the only additional personnel in the rehearsal room. "We also worked with a Deaf consultant who was, alongside Jamal, able to inform the process and offer advice on what would and wouldn't be accessible or important to a deaf audience. As a small ensemble we don't often have the ability to stretch our resources to include an outside eye to watch the process, but in this instance it was vital and so important in ensuring we made a high quality, accessible show". 
13 Apart from the linguistic and cultural issues, which were relatively easily resolved by learning BSL and employing a deaf consultant, the other major change to the rehearsal process concerned the script. "As a devising company, we often memorise our lines throughout rehearsals and write up the script in the last week, ready for the technical rehearsals. For Sirens it was important that we had the script earlier in the process, as most scenes had to be translated into BSL for us all to learn, and then back-translated into English for them to be put into the captions", a process that takes additional time. "Whereas often we create scenes that inform the show but might not make it into the final performance, every word felt very precious in this process, and getting them onto paper felt integral to that process".

Other impacts of casting a deaf actor within the ensemble were entirely beneficial. "As a devising theatre company, we often end up sitting around and chatting about things for far too long. This wasn't an option in this rehearsal room. We worked most effectively when we got up on our feet and just tried things. This made for a very proactive rehearsal room where it felt like we were making decisions and progressing through the piece really quickly". Additionally, working alongside a deaf actor allowed the hearing members of the company to develop not only their language competencies, but also their understanding of techniques for telling stories visually, a central plank of Zoo Co's theatricality. In particular the ensemble developed its skills in Visual Vernacular, a creative technique in which non-iconic signed language is eschewed in favour of mime with iconic gesture and the use of cinematic techniques such as closeups, long shots, shifting perspectives, role shift, freeze frame and slow motion. In Sirens, "Visual Vernacular ... became a really integral element to our story and character development. It was a skill none of us had ever used before and it was so exciting to develop a new technique within our existing physical storytelling style".

Casting a deaf actor also required the hearing performers to undertake deaf awareness training, and this linked "directly to creating a strong ensemble. We pride ourselves on our inclusive, supportive rehearsal room, and this was made stronger by ensuring every person in the room could contribute to conversation; that every person was empowered to collaborate on all aspects of the creative process; and that staging was suitable so that actors and audience could see signing clearly... Being an effective ensemble is about considering the needs of those you work with and ensuring those needs are catered to for the betterment of the whole process".

16 The aim of the creative process was "to ensure everyone who watched Sirens could connect to the story and characters as much as the person they were sitting next to". Central to this was the integrated use of BSL within the performances, not only by Ajala but also by the hearing actors. In performance this seamlessly merged with Zoo Co's trademark visual style. "As a company which enjoys using lots of different physical techniques to tell a story, we tried to up our game in terms of visual humour, visual vernacular and visual storytelling to ensure it was as entertaining as possible for all our audience. As we use clowning in our work, the over the top nature of the characters also lent itself well to the facial expressions that are so important in BSL".

17 Additionally the production was "creatively captioned", as an element of the projections used throughout the performance. "The captions were somewhat personalised, for example, one character's lines were always written in yellow, another character's in pink. Also the captions were placed close to the character that was speaking at the time. We hoped this would ensure as high a level of access as possible: 
we have all too often visited theatres where captions are placed so far from the stage that it is nearly impossible for the audience to read them and watch the show at the same time. We wanted to make sure they were fully integrated in the piece, which also meant we could play around with them and, at times, have the characters interact with the projected words and images".

One of the aims of Zoo Co's approach throughout Sirens was "to put a hearing audience, who are so used to watching a show that they can wholly access, into the shoes of deaf audience members who often encounter barriers when visiting the theatre. The captions ensured that the spoken scenes could be accessed by deaf spectators, and equally that the signed scenes could be accessed by those who couldn't use BSL. It was really interesting to speak to our hearing audiences after the show and see their reaction to being on the other side of things".

of course audience response is difficult to quantify, but feedback was generally positive. This was reflected by the critical response, for example the British Theatre Guide ${ }^{15}$ described Sirens as "signed and captioned, this is an inclusive show that doesn't feel laboured at any point ... [its] BSL-inclusive storyline and use of creative captions offered something to a deaf audience that was otherwise not available throughout the rest of the Fringe". One comment made repeatedly was the bravery of a company in highlighting the deaf experience in a show that also tackled queer relationships and sexual harassment. "Sirens unapologetically tackles all three of those and more. I think that often, theatre-makers are frightened to experiment with bringing in more than one topic in the fear that things might feel shoehorned in, but as we work in a devising process, all the experiences seen within Sirens are directly related to someone you see on stage and so came authentically into the show".

To summarise, then, in Sirens Zoo Co have extended their ambition for accessibility by the simple act of employing a deaf actor. Rather than side-lining him within the devising process, they created a rehearsal room that was fully inclusive, by learning BSL and by employing BSL/English interpreters and a Deaf consultant to represent the deaf audience at rehearsals. Each of these steps they took by thinking through the requirements both of working with a deaf actor and of creating material suitable for deaf spectators, a bottom up approach that in many ways successfully matches the guidelines for producing a signed language performance created by Miles and Fant (1976) and expanded upon by Allen (1977) ${ }^{16}$.

21 For Zoo Co, "the greatest takeaway from the experience has been the power of visual storytelling. We have always regarded ourselves as a highly visual company, but working with deaf people has shown us a whole new meaning to the word, and our work has flourished for it". Since creating Sirens, they "have gone on to make another BSL-inclusive family show, once again working with a deaf and hearing ensemble. Messy explores ADHD in young girls and is a very visual, inclusive show that is touring in Spring 2019". We will also be returning to Sirens ... as we take it on tour across the UK. Having a deaf actor is imperative to both of these shows, and we look forward to exploring how our ongoing work can continue to serve a deaf audience". Zoo Co's approach sends a strong message to other theatre-makers. "Overall the changes to the actual process in order to accommodate a deaf actor were quite minimal". As "devising processes are very much led by the people in the room, they inevitably adapt to suit those there". Working on Sirens "proved that, as long as you have the right people in the room, creating accessible work doesn't need to be the 
unachievable feat that it is often regarded as". Indeed, the lead artists of Zoo Co found it inspirational. "We hope to continue to build our output and continue to create work that stretches the boundaries of accessibility, until theatre becomes a place without barriers to anybody, and inclusive performances are the norm not the exception". Furthermore, they challenge others to do the same: "If it's possible for a company of our size, then larger, more established companies should be doing more".

\section{NOTES}

1. I use 'deaf' to encompass the wide range of audio-linguistic practices found within that community. Audiologically, deaf people may be born deaf, late deafened, deaf blind, hard of hearing, or hearing members of deaf families who use a signed language as a first language. They may use signed or spoken language, or a blend of both (although the focus of this interview is the use of signed languages in theatre).

2. Leith , E. (2016) Moving Beyond Words in Scotland's Corp-Oral Traditions: British Sign Language Storytelling Meets the 'Deaf Public Voice'. Ph.D. thesis. University of Edinburgh.

3. Wilson, M. (2006) Storytelling and Theatre: Contemporary Professional Storytellers and Their Art. Basingstoke: Palgrave Macmillan.

4. Miles, D. and Fant, L. J. (1976) Sign-language theatre and deaf theatre: New definitions and directions. Edited by Murphy, H. J. Northridge: California State University.

5. See http://www.ntd.org/

6. See for example Bragg, B. and Bergman, E. (2002) Lessons in Laughter. Washington DC: Gallaudet University Press.

7. See Stewart, I. M. (2015) My Years with the British Theatre of the Deaf 1963 - 1977. Brighton: Ian M. Stewart.

8. See Shaw, C. (2013) 'Speaking in the Language of Art': Soviet Deaf Theatre and the Politics of Identity during Khrushchev's Thaw', Slavonic \& East European Review, 91(4), pp. 759-786.

9. See Richardson, M. (2018) 'The Sign Language Interpreted Performance: A Failure of Access Provision for Deaf Spectators ', Theatre Topics, 28(1), pp. 63-74.

10. See http://www.deafwest.org/

11. See www.deafinitelytheatre.co.uk

12. See Richardson, M. (2017) 'An interview with the lead artists of the Deaf and Hearing Ensemble', Miranda, 14.

13. The text of the Act is available at www.legislation.gov.uk/asp/2015/11/enacted

14. Conley, W. (2001) 'Away from Invisibility, Toward Invincibility: Issues with Deaf Theatre Artists in America', in Bragg, L. (ed.) Deaf World: A Historical Reader and Primary Sourcebook. New York: New York University Press, pp. 51-67.

15. https://www.britishtheatreguide.info/reviews/sirens-pleasance-court-16419

16. Allen, D. K. (1977) A Procedure for Directing a Sign Language Theatre Production for a Child Audience. Master of Arts thesis. California State University, Northridge. 


\section{ABSTRACTS}

Interview with Rosalind Hoy of Zoo Co, outlining the decision to work with a deaf actor, and exploring the impact on the company and its creative processes.

Entretien avec Rosalind Hoy de Zoo Co qui revient sur la décision de la compagnie de travail avec un comédien sourd. Les conséquences de ce choix sur le travail de la compagnie et son processus de création sont abordées.

\section{INDEX}

Subjects: Theater

Keywords: Zoo Co, Sirens, deaf theatre, signed language theatre, captions, accessibility, audience engagement

Mots-clés: Zoo Co, Sirens, theatre sourd, théâtre en langue des signes, sous-titrage, accessibilité, implication du public

\section{AUTHOR}

\section{MICHAEL RICHARDSON}

School of Social Science, Heriot-Watt University, Edinburgh

PhD Candidate

mr38@hw.ac.uk 